\title{
ADUBAÇÃo NA PRODUÇÃo DE PLÂNTULAS DO MARMELEIRO 'Japonês'
}

\author{
Fertilization in the production of seedlings of 'japanese' quince tree
}

\author{
João Paulo Vanin ${ }^{1}$, Rafael Pio ${ }^{2}$, Edvan Alves Chagas ${ }^{3}$, Wilson Barbosa ${ }^{4}$, \\ Idiana Marina Dalastra1, Fábio Albuquerque Entelmann ${ }^{5}$
}

\begin{abstract}
RESUMO
Conduziu-se este trabalho, com o objetivo de verificar a ação da adubação por cobertura e por liberação lenta, no crescimento de plântulas do marmeleiro 'Japonês'. Sementes do marmeleiro 'Japonês' foram estratificadas à frio-úmido por 30 dias e, em seguida, foram dispersas em bandejas de poliestireno de 72 células (células com capacidade de $120 \mathrm{~cm}^{3}$, uma semente por célula), contendo Vermiculita ${ }^{\circledR}$ de grânulos finos como substrato. No primeiro experimento, a Vermiculita ${ }^{\circledR}$ foi acrescida de diferentes doses do adubo de liberação lenta Basacot ${ }^{\circledR}$ (15-8-12): 0, 3, 6, 9, 12 e $15 \mathrm{~kg} \mathrm{~m}^{-3}$ de substrato. No segundo experimento, as sementes foram dispersas em bandejas similares, preenchidas com Vermiculita ${ }^{\circledR}$ e passados 30 dias da semeadura, foram realizadas adubações por cobertura com nitrogênio na forma de uréia (45\% de N), via água de irrigação: 0, 300,600, 900, 1200 e $1500 \mathrm{mg} \mathrm{dm}^{-3}$. As aplicações foram parceladas em duas vezes em intervalos de 10 dias, adicionada em cada célula $10 \mathrm{~mL}$ de solução por aplicação. As bandejas permaneceram dentro de telado constituído de sombrite $50 \%$ de luminosidade e foram irrigadas diariamente. Aos 60 dias após a semeadura, foi mensurada a porcentagem de emergência, o comprimento médio das plântulas, número médio de folhas, massa seca média da parte aérea e total das plântulas. Concluiu-se que a adição de $9 \mathrm{~kg}$ de Basacot $^{\circledR} \mathrm{em}$ cada $^{-3}$ de Vermiculita ${ }^{\circledR}$ favoreceu o melhor desenvolvimento das plântulas.
\end{abstract}

Termos para indexação: Chaenomeles sinensis Koehne, porta-enxerto e nutrição.

\begin{abstract}
The objective of the present work was to verify the effect of the fertilizations by covering and slow liberation, on the growth of seedlings of the 'Japanese' quince tree. Seeds of the 'Japanese' underwent cold-humid stratification for 30 days and were then dispersed in polystyrene trays of 72 cells (cells with capacity of $120 \mathrm{~cm}^{3}$, one seed for cell), containing thin granule Vermiculite ${ }^{\circledR}$ as substrate. In the first experiment, we added to Vermiculite ${ }^{\circledR}$ different doses of the fertilizer of slow liberation $\operatorname{Basacot}^{\circledR}(15-8-12)$ : 0, $3,6,9,12$ and $15 \mathrm{~kg} \mathrm{~m}^{-3}$ of substrate. In the second experiment, the seeds were dispersed in similar trays and filled with Vermiculite ${ }^{\circledR}$ ; after 30 days, fertilizations was accomplished by covering with nitrogen in the form of urea $(45 \% \mathrm{~N})$, through irrigation water: 0 , $300,600,900,1200$ and $1500 \mathrm{mg} \mathrm{dm}^{-3}$. The applications were parceled out in twice, in intervals of 10 days, and in each application, $10 \mathrm{~mL}$ of solution were added in each cell. The trays were kept under shading sieve (50\% shading), being irrigated periodically. 60 days after seeding, the emergency percentage, the average length of the seedlings, average number of leaves, shoot dry matter and total seedlings were evaluated. It was concluded that adding $9 \mathrm{~kg}$ of Basacot ${ }^{\circledR}$ to each $\mathrm{m}^{-3}$ of Vermiculite ${ }^{\circledR}$ favored the best development of the seedlings.
\end{abstract}

Index termex: Chaenomeles sinensis Koehne, rootstock and nutrition.

(Recebido em 15 de setembro de 2008 e aprovado em 30 de julho de 2009)

\section{INTRODUÇÃOO}

Recentemente, a Empresa de Pesquisa Agropecuária de Minas Gerais (EPAMIG), vem estudando o marmeleiro 'Japonês' (Chaenomeles sinensis Koehne) como opção de porta-enxertos para marmeleiros, frente ao elevado número de sementes por frutos (acima de 180), alta emergência das plântulas, elevado vigor no viveiro e boa afinidade na relação enxerto/porta-enxerto com alguns cultivares em observações preliminares à campo ( Pio et al., 2005, 2007c; Campo Dall'Orto et al., 2007; Entelmann et al., 2009; Pio et al., 2009).

As pesquisas revelaram que o marmeleiro 'Japonês' não possui boa capacidade de enraizamento de suas estacas (Pio et al., 2004, 2005, 2007b). Por esse motivo, foi desenvolvido um protocolo de produção de mudas enxertadas de marmeleiro, utilizando o porta-enxerto 'Japonês' produzido por sementes (Pio et al., 2007a).

No processo de produção do porta-enxerto 'Japonês', demandam-se nove meses até o ponto de enxertia

\footnotetext{
1Universidade Estadual do Oeste do Paraná/UNIOESTE - Marechal Cândido Rondon, PR

2Universidade Federal de Lavras/UFLA - Departamento de agricultura/DAG - Cx. P. 3037 - 37200-000 - Lavras, MG - rafaelpio@dag.ufla.br ${ }^{3}$ Centro Avançado de Pesquisa Tecnológica do Agronegócio de Frutas - Instituto Agronômico/IAC - Jundiaí, SP

${ }^{4}$ Centro Experimental Central - Instituto Agronômico/IAC - Campinas, SP

${ }^{5}$ Universidade de São Paulo, Escola Superior de Agricultura “Luiz de Queiroz"/USP/ESALQ - Deptamento de Produção Vegetal - Piracicaba-SP
} 
(diâmetro superior a sete $\mathrm{mm}$ ), desde a extração das sementes e estratificação à frio-úmido, semeadura em bandejas e posterior transplantio para as sacolas plásticas (Pio et al., 2007c).

No que tange à qualidade do porta-enxerto, a nutrição das plântulas é fundamental para o crescimento de forma satisfatória e menor estresse no processo de transplantio, garantindo que os porta-enxertos possuam bom desenvolvimento (Marschner, 1997). No entanto, não se conhece a exigência nutricional do marmeleiro 'Japonês' na fase de viveiro, o que vem acarretando maior tempo de permanência das plântulas nas bandejas, na fase que precede o transplantio para as sacolas plásticas.

Além do mais, a adubação criteriosa do portaenxerto 'Japonês' poderá garantir que os mesmos cheguem ao ponto de enxertia precocemente, reduzindo o tempo de permanência das mudas no viveiro e, consequentemente preconizando o sistema propagativo do marmeleiro.

Assim, neste trabalho, objetivou-se verificar a ação da adubação nitrogenada por cobertura e por fertilizante de liberação lenta, no crescimento de plântulas do marmeleiro 'Japonês'.

\section{MATERIAL E MÉTODOS}

Os experimentos foram conduzidos na Universidade Estadual do Oeste do Paraná (UNIOESTE), campus de Marechal Cândido Rondon-PR, entre os meses de setembro à novembro de 2007. Sementes do marmeleiro 'Japonês' foram extraídas de frutos maduros coletados na Estação Experimental de Maria da Fé, da Empresa Agropecuária de Minas Gerais (EPAMIG), Maria da FéMG, em maio do mesmo ano. As sementes foram lavadas e secas à sombra e, posteriormente, armazenadas em baixa temperatura por quatro meses.

Decorrido esse período, as sementes foram distribuídas entre camadas de algodão umedecido e colocadas em placas de Petri (dimensões de 90 x $15 \mathrm{~mm}$ ), para estratificação a frio-úmido em câmara tipo B.O.D. (temperatura média de $4^{\circ} \mathrm{C}$ ) por 30 dias. Em seguida, as sementes foram dispersas em bandejas de poliestireno de 72 células (células com capacidade de $120 \mathrm{~cm}^{3}$ ), contendo a Vermiculita $^{\circledR}$ expandida de grânulos médios como substrato.

No primeiro experimento, a Vermiculita ${ }^{\circledR}$ foi acrescida de diferentes doses do fertilizante de liberação lenta $\operatorname{Basacot}^{\circledR}$ (15-8-12): 3, 6, 9, 12 e $15 \mathrm{~kg} \mathrm{~m}^{-3}$ de substrato. O Basacot $^{\circledR}$ é um fertilizante com tempo de liberação de dois meses que, além de conter $15 \%$ de $\mathrm{N}, 8 \%$ de $\mathrm{P}_{2} \mathrm{O}_{5}$ e $12 \%$ $\mathrm{K}_{2} \mathrm{O}$, apresenta ainda em sua formulação $1,2 \%$ de $\mathrm{Mg}, 5 \%$ de $\mathrm{S}, 0,4 \%$ de $\mathrm{Fe}, 0,02 \%$ de $\mathrm{B}, 0,05 \%$ de $\mathrm{Cu}, 0,06 \%$ de $\mathrm{Mn}$ e $0,015 \%$ de Mo. Em seguida, as sementes foram dispersas individualmente nas células.
No segundo experimento, as sementes foram dispersas individualmente em células de $120 \mathrm{~cm}^{3}$ (bandejas de 72 células), preenchidas com Vermiculita ${ }^{\circledR}$ e passados 30 dias da semeadura, foram realizadas adubações por cobertura com nitrogênio na forma de uréia ( $45 \%$ de N), via água de irrigação, nas seguintes dosagens: 300, 600, 900, 1200 e $1500 \mathrm{mg} \mathrm{dm}^{-3}$. As aplicações foram parceladas em duas vezes em intervalos de 10 dias, adicionada em cada célula $10 \mathrm{~mL}$ de solução por aplicação.

As bandejas permaneceram dispostas em bancadas suspensas de 1,2 m, dentro de um telado constituído de sombrite $50 \%$ de luminosidade e foram irrigadas diariamente.

O delineamento adotado em ambos os experimentos foi o inteiramente casualizado, com seis tratamentos (cinco doses de $\mathrm{N}$ por cobertura e do fertilizante de liberação lenta Basacot $^{\circledR}$, além da testemunha sem adição de tratamento), cinco repetições e 12 sementes por parcela, totalizando 360 sementes em cada experimento.

Após 60 dias da semeadura, foi mensurada a porcentagem de emergência, o comprimento médio das plântulas (com auxílio de escalímetro), número médio de folhas, massa seca média da parte aérea e massa seca média total das plântulas, por meio da secagem do material vegetal em estufa de circulação de ar forçado à $65^{\circ} \mathrm{C}$, durante 48 horas e posterior pesagem em balança analítica.

Os dados foram submetidos à análise de variância pelo teste $\mathrm{F}$ e as médias foram submetidas a regressão linear ou quadrática, de acordo com as indicações de Gomes (2000), utilizando-se do Sistema para Análise de Variância - SISVAR (Ferreira, 2000).

\section{RESULTADOS E DISCUSSÃO}

Por meio da análise de variância, ficou evidenciado pelo teste $\mathrm{F}$ que houve diferença estatística para todas as variáveis analisadas, tanto para a suplementação com uréia por cobertura (Tabela 1) como para a incorporação ao substrato com Basacot ${ }^{\circledR}$ (Tabela 2).

Para a avaliação da porcentagem de emergência, praticamente não houve diferença entre a testemunha e a dose $361,36 \mathrm{mg} \mathrm{dm}^{-3}$ (84\% e $86,8 \%$ de emergência, respectivamente); no entanto, com o aumento crescente da suplementação com uréia, houve decréscimo da porcentagem da emergência, registrando-se $58 \%$ com a dose de $1500 \mathrm{mg} \mathrm{dm}^{-3}$ (Figura 1A). Já, para o experimento de suplementação com fertilizante de liberação lenta Basacot $^{\circledR}$, constatou-se que a emergência foi superior a $78 \%$ em todos os tratamentos utilizados, com $91 \%$ de emergência sem a adição do fertilizante, $84 \%$ com a dose 3 $\mathrm{kg} \mathrm{m}^{-3}$ e $80 \%$ com a dose $6 \mathrm{~kg} \mathrm{~m}^{-3}$ (Figura 1B). 
Tabela 1 - Resumo da análise de variância para: Porcentagem de emergência (PE), comprimento da parte aérea (CPA), número de folhas (NF), massa seca da parte aérea (MSPA) e massa seca total (MST) de plântulas do marmeleiro 'Japonês' por meio da adubação com nitrogênio na forma de uréia. Marechal Cândido Rondon-PR, UNIOESTE, 2008.

\begin{tabular}{lcccccc}
\hline \multirow{2}{*}{ FV } & \multirow{2}{*}{ GL } & \multicolumn{5}{c}{ Quadrado Médio } \\
\cline { 3 - 7 } & & PE & CPA & NF & MSPA & MST \\
\hline Uréia & 5 & $557,36^{*}$ & $4,28^{*}$ & $9,79^{*}$ & $156,84^{*}$ & $277,50^{*}$ \\
Resíduo & 24 & 51,92 & 0,13 & 0,21 & 34,28 & 55,19 \\
\hline C.V. $(\%)$ & --- & 9,22 & 4,60 & 6,21 & 10,08 & 10,60 \\
\hline
\end{tabular}

${ }^{\mathrm{ns}}$ não significativo pelo teste $\mathrm{F} ; *$ significativo pelo teste $\mathrm{F}(\mathrm{P} \geq 0,05)$.

Tabela 2 - Resumo da análise de variância para: Porcentagem de emergência (PE), comprimento da parte aérea (CPA), número de folhas (NF), massa seca da parte aérea (MSPA) e massa seca total (MST) de plântulas do marmeleiro 'Japonês' por meio da adubação com nitrogênio da aplicação do adubo de liberação lenta Basacot $^{\circledR}$. Marechal Cândido Rondon-PR, UNIOESTE, 2008.

\begin{tabular}{lcccccc}
\hline \multirow{2}{*}{ FV } & \multirow{2}{*}{ GL } & \multicolumn{5}{c}{ Quadrado Médio } \\
\cline { 3 - 7 } & & PE & CPA & NF & MSPA & MST \\
\hline Basacot $^{\circledR}$ & 5 & $186,93^{*}$ & $29,96^{*}$ & $5,63^{*}$ & $521,59^{*}$ & $712,70^{*}$ \\
Resíduo & 24 & 60,41 & 1,04 & 0,42 & 28,80 & 40,51 \\
\hline C.V. $(\%)$ & --- & 9,41 & 7,79 & 6,34 & 13,18 & 12,23 \\
\hline
\end{tabular}

${ }^{\mathrm{ns}}$ não significativo pelo teste $\mathrm{F} ; *$ significativo pelo teste $\mathrm{F}(\mathrm{P} \geq 0,05)$.
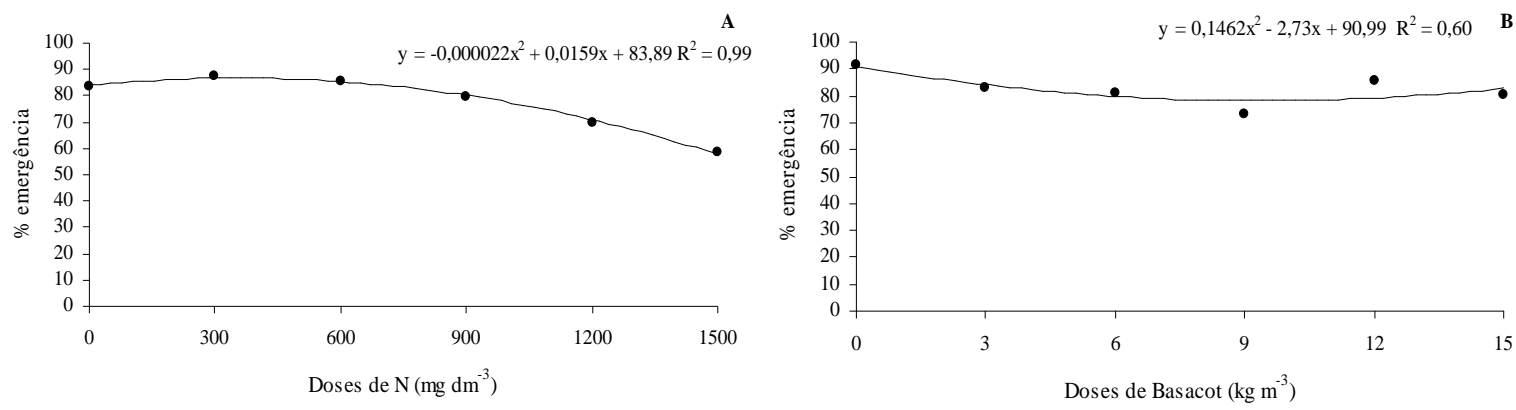

Figura 1 - Porcentagem de emergência de plântulas do marmeleiro 'Japonês' por meioda adubação com nitrogênio na forma de uréia (A) e adubo de liberação lenta $\operatorname{Basacot}^{\circledR}$ (B). Marechal Cândido Rondon-PR, UNIOESTE, 2008.

Por esses resultados, nota-se que a utilização de fertilizante de liberação lenta e a suplementação com nitrogênio em cobertura, em doses crescentes, ocasiona diminuição da porcentagem de emergência. Esses resultados podem ser atribuídos à queima das raízes, ocasionando mortalidade das plântulas e, consequentemente, diminuição da quantidade final de plântulas do porta-enxerto.

$\mathrm{O}$ nitrogênio é um dos nutrientes requeridos em maior quantidade pelas plântulas na fase de viveiro, participando dos principais processos metabólicos da planta (Maust \& Williamson, 1994). Resultados de pesquisa têm demonstrado resposta positiva à aplicação de fertilizantes nitrogenados sobre o desenvolvimento de porta-enxertos de citros produzidos em bandejas ou tubetes, especialmente quando realizada de forma parcelada em pequenas doses (Carvalho \& Souza, 1996), minimizando as perdas por lixiviação e volatilização.

Para o comprimento médio das plântulas, melhores resultados foram obtidos com a utilização de $200 \mathrm{mg} \mathrm{dm}^{-3}$

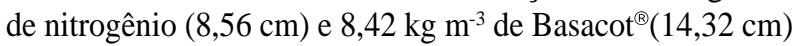
(Figura 2A e 2B). Em ambos os experimentos, a adição crescente de nitrogênio, via água de irrigação ou via fertilizante de liberação lenta, a partir dessas doses 
mencionadas, ocasionaram decréscimo do comprimento médio das plântulas. Consequentemente, para o número médio de folhas, houve similaridade dos resultados $(366,67$ $\mathrm{mg} \mathrm{dm}^{-3}$ de nitrogênio obtiveram-se 8,53 folhas e 9,42 kg m${ }^{3}$ de Basacot ${ }^{\circledR} 11$ folhas) (Figura 3A e 3B).

Esses resultados concordam com Carvalho (1998), que afirma dever-se evitar superdosagens na produção de plântulas, por ocasionarem queima das folhas e do caule e ainda o desbalanço nutricional.

A comparação geral dos resultados obtidos pela testemunha com os dos demais tratamentos demonstra claramente a importância da adubação para a produção das plântulas; a ausência de suplementação mineral comprometeu o crescimento, que apresentaram desempenho inferior em comparação as plântulas adubadas. Segundo Decarlos Neto et al. (2002), a utilização do nitrogênio para produção de mudas em recipientes, tem proporcionado um rápido crescimento destas na fase de sementeira.

Para a massa seca média da parte aérea e total das plântulas do marmeleiro 'Japonês', a suplementação com doses crescentes de nitrogênio por cobertura promoveu decréscimo dos resultados; para a massa seca média da parte aérea, foi obtido $253,49 \mathrm{mg}$ com a suplementação com $890 \mathrm{mg} \mathrm{dm}^{-3}$ e 112,53 mg com $1500 \mathrm{mg} \mathrm{dm}^{-3}$ (perda de $140,96 \mathrm{mg}$ ) (Figura 4A). Para a massa seca média total das plântulas, registrou-se $311,45 \mathrm{mg}$ de massa seca com a testemunha, 274,37 mg com a suplementação de $300 \mathrm{mg}$ $\mathrm{dm}^{-3}$ (perda de $37,08 \mathrm{mg}$ ) e $126,05 \mathrm{mg}$ com $1500 \mathrm{mg} \mathrm{dm}^{-3}$ (perda de 185,43 mg) (Figura 4B).

A suplementação com nitrogênio por cobertura, possivelmente, favoreceu a diminuição do $\mathrm{pH}$ do substrato, ocasionado por uma possível liberação do $\mathrm{H}^{+}$produzido durante o processo de nitrificação da uréia aplicada, conforme é relatado por Decarlos Neto et al. (2002), ou ter ocasionado um desequilíbrio nutricional pelo excesso do $\mathrm{N}$ nas plantas.

Vale ressaltar que as espécies frutíferas possuem comportamento distinto quanto a necessidade de nitrogênio durante a fase de sementeira, conforme observase pelo trabalho de Decarlos Neto et al. (2002), que observaram efeito positivo da aplicação de nitrogênio no substrato de cultivo, sobre o crescimento dos portaenxertos 'Tangelo Orlando', limoeiros 'Cravo' e 'Volkameriano' e tangerineiras 'Cleópatra' e 'Sunki', sendo as doses de $1110 ; 1240 ; 1410 ; 1100$ e $1140 \mathrm{mg} \mathrm{dm}^{-3} \mathrm{de}$
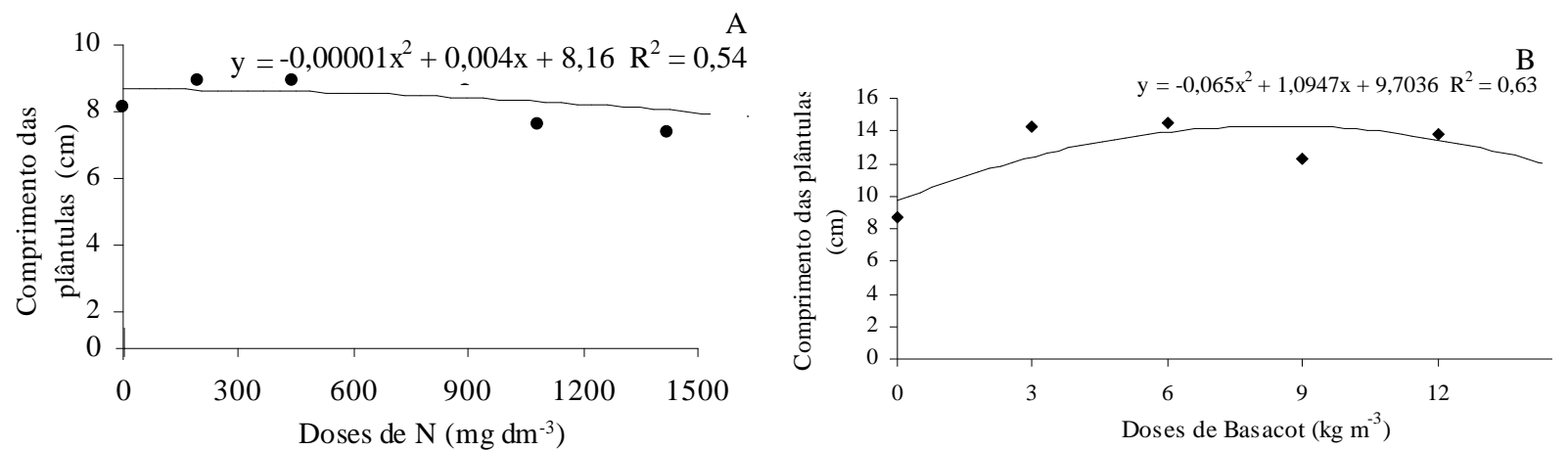

Figura 2 - Comprimento da parte aérea de plântulas do marmeleiro 'Japonês' por meio da adubação com nitrogênio na forma de uréia (A) e adubo de liberação lenta $\operatorname{Basacot}^{\circledR}$ (B). Marechal Cândido Rondon-PR, UNIOESTE, 2008.

A

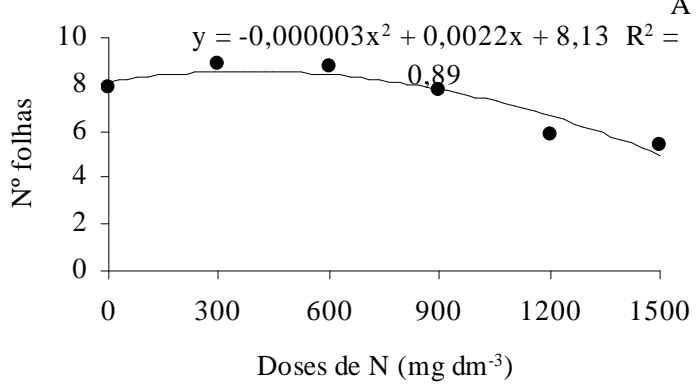

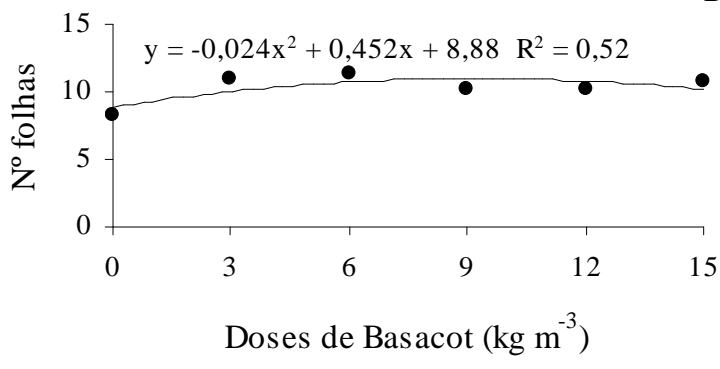

Figura 3 - Número de folhas de plântulas do marmeleiro 'Japonês' por meio da adubação com nitrogênio na forma de uréia (A) e adubo de liberação lenta Basacot $^{\circledR}$ (B). Marechal Cândido Rondon-PR, UNIOESTE, 2008. 
nitrogênio responsáveis pelo máximo crescimento em altura destes porta-enxertos, respectivamente.

Já, para a aplicação do fertilizante de liberação lenta junto ao substrato, os resultados foram diferenciados para a massa seca média da parte aérea e total das plântulas do marmeleiro 'Japonês', em comparação a suplementação por cobertura; para a massa seca média da parte aérea, foi obtido $271,91 \mathrm{mg}$ de massa seca com a testemunha, $475,52 \mathrm{mg}$ com a utilização de $10,67 \mathrm{~kg} \mathrm{~m}^{-3}$ de Basacot $^{\circledR}$ (incremento de 203,61 mg) (Figura 5A). Para a massa seca média total das plântulas, registrou-se $372,35 \mathrm{mg}$ de massa seca sem a utilização de Basacot e 616,61 mg com a suplementação de $8,75 \mathrm{~kg} \mathrm{~m}^{-3}$ (incremento de 244,26 mg) (Figura 5B).

Verifica-se que houve aumento dessas variáveis analisadas até um ponto ótimo, por meio da aplicação de
Basacot $^{\circledR}$. Entretanto, altas dosagens de Basacot $^{\circledR}$ proporcionaram ganhos menores, em comparação com a testemunha na massa seca das plântulas de marmeleiro 'Japonês'.

Os resultados obtidos com a utilização do fertilizante de liberação lenta em comparação com a suplementação com nitrogênio por cobertura, via água de irrigação, foi superior em todas as variáveis analisadas. Esses resultados podem estar relacionados ao fato da formula do Basacot ${ }^{\circledR}$ conter outros macro e micronutrientes essenciais às plântulas do marmeleiro 'Japonês' e também pela característica da forma de liberação dos fertilizantes ser aos poucos, sendo a liberação complementar a lixiviação imposta pela irrigação, durante a produção das plântulas do marmeleiro 'Japonês'.
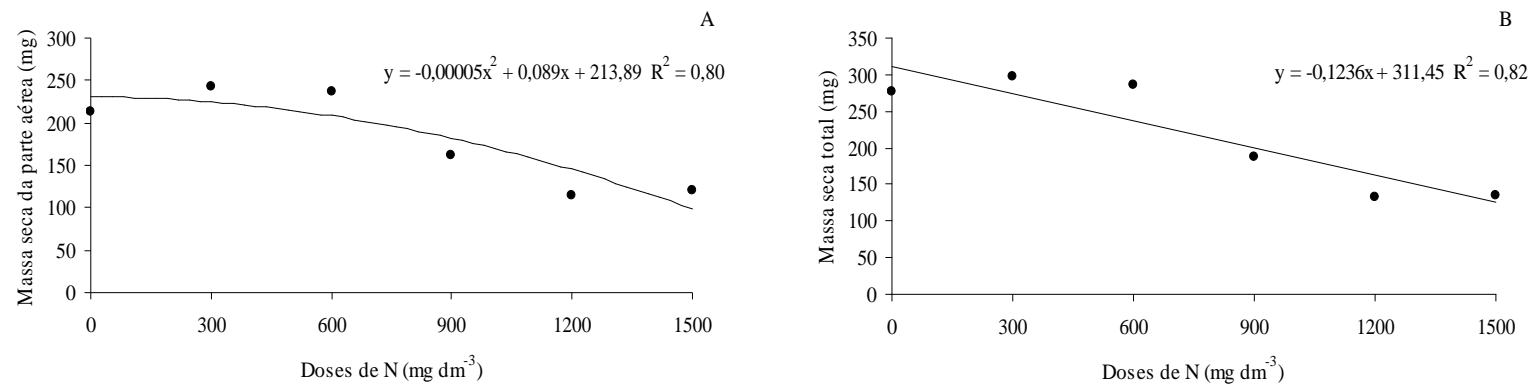

Figura 4 - Massa seca média da parte aérea (A) e total (B) de plântulas do marmeleiro 'Japonês' por meio da adubação com nitrogênio na forma de uréia. Marechal Cândido Rondon-PR, UNIOESTE, 2008.
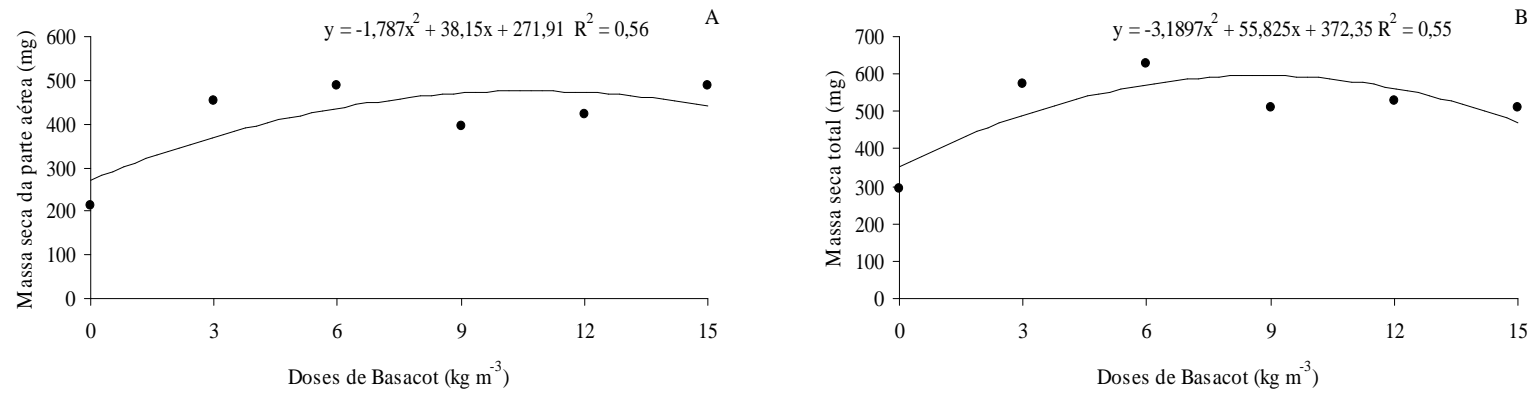

Figura 5 - Massa seca média da parte aérea (A) e total (B) de plântulas do marmeleiro 'Japonês' por meio da utilização do adubo de liberação lenta Basacot ${ }^{\circledR}$. Marechal Cândido Rondon-PR, UNIOESTE, 2008. 
VANIN, J. P. et al.

\section{CONCLUSÃO}

Por meio dos resultados obtidos, concluiu-se que: - A adição de $9 \mathrm{~kg}$ de Basacot $^{\circledR}$ em cada $\mathrm{m}^{-3}$ de Vermiculita $^{\circledR}$ favoreceu o melhor desenvolvimento das plântulas do marmeleiro 'Japonês';

- Suplementações com 360 mg dm ${ }^{-3}$ de nitrogênio permitiram a maior porcentagem de emergência e número de folhas, $200 \mathrm{mg} \mathrm{dm}^{-3}$ maior comprimento da parte aérea e $890 \mathrm{mg} \mathrm{dm}^{-3}$ de nitrogênio maior acúmulo de massa seca na parte aérea;

- A adição com Basacot $^{\circledR}$, junto à vermiculita, propicia resultados mais expressivos em comparação com a suplementação com nitrogênio por cobertura, na forma de uréia, na produção de plântulas do marmeleiro 'Japonês'.

\section{REFERÊNCIAS BIBLIOGRÁFICAS}

CAMPO DALL'ORTO, F. A. ; OJIMA, M.; PIO, R.; CHAGAS, E. A.Avaliação da capacidade reprodutiva de algumas cultivares de marmeleiros visando a obtenção de porta-enxertos. Ciência e Agrotecnologia, Lavras, v.31, n.2, p.274-278, mar./abr., 2007

CARVALHO, S.A. Estratégias para estabelecimento de matrizes, borbulheiras e viveiros de citros em ambiente protegido. In: DONADIO, L.C.; RODRIGUEZ, O. (Eds.). In: SEMINÁRIO INTERNACIONAL DE CITROS TRATOS CULTURAIS, 5., 1998, Bebedouro. Anais... Bebedouro: Fundação Cargill, 1998. p.67-101.

CARVALHO, S.A.; SOUZA, M. Doses e frequiência de aplicação de nitrato de potássio no crescimento de limoeiro 'Cravo' e da tangerineira 'Cleópatra' em bandejas. Pesquisa Agropecuária Brasileira, Brasília, v.31, n.11, p.815-822, 1996.

DECARLOS NETO, A.; SIQUEIRA, D.L. de; PEREIRA, P.R.G.; ALVAREZ, V.H. Crescimento de porta-enxertos de citros em tubetes influenciados por doses de N. Revista Brasileira de Fruticultura, Cruz das Almas, v.24, n.1, p.199-203, 2002.

ENTELMANN, F. A.; PIO, R.; CHAGAS, E. A., SCARPARE FILHO, J. A.; ALVARENGA, A. A.; ABRAHÃO, E. Estratificação à frio de sementes de 'Japonês', portaenxerto para marmeleiros. Ciência e Agrotecnologia, Lavras, v.33, Edição Especial, p.1877-1882, 2009.

FERREIRA, D.F. Análise estatística por meio do SISVAR (Sistema para Análise de Variância) para Windows versão 4.0. In: REUNIÃO ANUAL DA REGIÃO BRASILEIRA DA SOCIEDADE INTERNACIONAL DE BIOMETRIA, 45., 2000, São Carlos. Anais...São Carlos: UFSCar, 2000. p.255-258.
GOMES, F.P. Curso de estatística experimental. 14.ed. Piracicaba: USP/ESALQ, 2000. 477p.

MARSCHNER, H. Mineral nutrition of higher plants. 2.ed. San Diego: Academic, 1997. 889p.

MAUST, B.E.; WILLIAMSON, J.G. Nitrogen nutrition of containerized citrus nursery plants. Journal of the American Society for Horticultural Science,

Alexandria, v.119, n.1, p.195-201, 1994.

PIO, R.; ARAÚJO, J.P.C.; SCARPARE FILHO, J.A.; MOURÃO FILHO, F.A.A.; ALVARENGA, A.A.;

ABRAHÃO, E. Potencial de propagação de cultivares de marmeleiro por estaquia. Revista Brasileira de

Fruticultura, Cruz das Almas, v.26, n.2, p.287-289, 2004.

PIO, R.; CAMPO DALL'ORTO, F.A.; ALVARENGA, A.A.; ABRAHÃO, E.; BUENO, S.C.S.; MAIA, M.L.; CHAGAS, E.A. Marmelo: do plantio da marmelada. Campinas: CATI, 2007a. 49p. (Boletim técnico, 248).

PIO, R.; CAMPO DALL'ORTO, F.A.; ALVARENGA, A.A.; ABRAHÃO, E.; CHAGAS, E.A.; SIGNORINI, G. Propagação do marmeleiro 'Japonês' por estaquia e alporquia realizadas em diferentes épocas. Ciência e Agrotecnologia, Lavras, v.31, n.2, p.570-574, 2007b.

PIO, R.; CHAGAS, E. A.; BARBOSA, W.; SIGNORINI, G.; AGUILA, J. S. D. Teste de porta-enxertos intergenéricos para marmeleiros em condições de viveiro. Ciência e

Agrotecnologia, Lavras, v. 33, n. 2, p. 521-526, mar./abr., 2009.

PIO, R.; CHAGAS, E.A.; BARBOSA, W.; SIGNORINI, G.; ALVARENGA, A.A.; ABRAHÃO, E.; CAZETTA, J.O.; ENTELMANN, F.A. Emergência e desenvolvimento de plântulas de cultivares de marmeleiro para uso como porta-enxertos. Revista Brasileira de Fruticultura, Cruz das Almas, v.29, p.133-136, 2007c.

PIO, R.; CHAGAS, E.A.; CAMPO DALL'ORTO, F.A.; BARBOSA, W.; ALVARENGA, A.A.; ABRAHÃO, E. Marmeleiro 'Japonês': nova opção de porta-enxerto para marmelos. O Agronômico, Campinas, v.57, p.15-16, 2005.

PIO, R.; RAMOS, J. D.; CHALFUN, N. N. J.; GONTIJO, T. C. A.; CARRIJO, E. P.; MENDONÇA, V.; ALVARENGA, A.A.; ABRAHÃO, E. Enraizamento de estaca dos marmeleiros 'Portugal' e 'Japonês' em diferentes ambientes e posições no recipiente. Ciência e Agrotecnologia, Lavras, v. 29 , n. 5, p. 968-973, set./out., 2005. 